Max-Planck-Institut für demografische Forschung

Max Planck Institute for Demographic Research

Konrad-Zuse-Strasse 1 - D-18057 Rostock · GERMANY

Tel +49 (0) 3812081 - 0; Fax +49 (0) 3812081 - 202;

http://www.demogr.mpg.de

MPIDR WORKING PAPER WP 2005-026

AUGUST 2005

\title{
Evidence of recent fertility decline \\ in Eritrea: \\ an analysis of trends and determinants
}

Gebremariam Woldemicael

This working paper has been approved for release by: Gerda Ruth Neyer (neyer@ demogr.mpg.de)

Deputy Head of the Laboratory of Contemporary European Fertility and Family Dynamics.

(C) Copyright is held by the authors.

Working papers of the Max Planck Institute for Demographic Research receive only limited review. Views or opinions expressed in working papers are attributable to the authors and do not necessarily reflect those of the Institute. 


\title{
EVIDENCE OF RECENT FERTILITY DECLINE IN ERITREA: AN ANALYSIS OF TRENDS AND DETERMINANTS
}

\author{
Gebremariam Woldemicael
}

\begin{abstract}
This paper contributes to an improved understanding of the recent fertility decline in Eritrea and the possible factors underlying it. Based on data from the 2002 Eritrea Demographic and Health Survey (EDHS), it offers increased clarity as to whether the recent decline indicates the onset of a long-term fertility transition or if it is merely a short-term response to the border conflict with Ethiopia (mid1998-2000). Various methods, including period trend analyses by age and parity, cohort fertility analysis, and multivariate statistical methods, are used to assess the extent of the decline and to identify major contributors to it. The evidence from this study indicates that fertility decline has started in Eritrea and that it has occurred in urban and rural areas, and in every region of the country. The decline is evident across all reproductive ages and birth orders, but is stronger among older mothers and for higher-order births. A prolonged spacing of births, cessation of further childbearing, and delayed age at marriage are the main contributors to the overall fertility decline. The study also reveals that the fertility decline started in the mid-1990s, well before the conflict, but it was faster during the peak years of the border conflict (1999-2000). This suggests that the reduction in fertility is not primarily an outcome of the border conflict (nor a temporary phenomenon), but that it might be the beginning of a long-term fertility transition, which was then accelerated by the border war and the associated social and economic crisis.
\end{abstract}




\section{INTRODUCTION}

Even though there is an increasing evidence of fertility decline in many sub-Saharan African countries (see, for example: Mturi and Hinde, 1994; Caldwell and Caldwell, 2001; Kirk and Pillet, 1998; Hinde and Mturi, 2000), it is not still clear whether fertility has begun to decline in Eritrea. Additionally, very little is known about the determinants of fertility in the country today. This is due to the recurrent war crises in the country - the thirty years war for independence (1961-91) and the recent border conflict with Ethiopia (1998-2000) - and to the unavailability of adequate data. Particularly, the period from mid-1998 to 2001 was one of war and economic crisis with large military mobilization, population displacement, severe disruption of the economy, and high inflation caused by the border conflict. This conflict disrupted not only the socio-economic progress that had been made after independence in 1991, but also the data collection systems. The border war, for example, prevented the undertaking of a modern population census that had been planned for 1998. At present, no adequate estimates exist for even the most basic aspects of the Eritrean population (such as size, rate of growth, birth and death rates) except for the reports on fertility and child mortality from the 1995 and 2002 EDHS surveys (NSEO and ORC Macro, 1997, 2003) and one recent paper on fertility decline in Eritrea and its prospects for the future (Blanc, 2004) based on the later EDHS survey. In general, the investigation of demographic aspects in the country, especially of fertility, is sketchy. The estimates made by the National Statistics and Evaluation Office (NSEO) and ORC Macro (1997, 2003) suggest that total fertility (TFR) declined from 6.1 to 4.8 between mid-1990s and the beginning of the new century. The study by Blanc (2004) indicates that TFR declined from 6.4 in 1994/95 to 4.4 in 2000/01. According to these crude TFR estimates, it appears that Eritrea has experienced a decline in fertility. But, although TFR is a good aggregate measure of fertility that controls for age composition and is useful to compare populations with different age structures, it is not robust enough to discern whether fertility change can be attributed to changing reproductive pattern at low or high parities (Njogu and Martin, 1991) or to trace changes in fertility behavior by various socio-economic characteristics (Luther and Pejaranoda, 1991). Thus, a more comprehensive examination of fertility trends is necessary. By applying the Bongaarts's proximate determinants model (Bongaarts, 1978) to the EDHS data to examine the relative contribution of each proximate 
variable, Blanc (2004) concluded that the recent fertility decline is mainly due to the impacts of the border conflict, which not only increased the proportion of spousal separation but also delayed age at marriage. Whether such impacts would be observed when other more specific factors - including birth order, and timing or spacing of births - and other fertility behaviors were investigated using a multivariate model that controls for various socio-demographic determinants of fertility is not clear. In view of the above uncertainties regarding recent trends and causes of the decline, a more comprehensive analysis is essential.

In this paper, further analysis is made to investigate recent fertility trends in Eritrea and to discover what factors underlie the change to low fertility. More robust methods of fertility analysis, including age- and parity-specific trend analyses, and cohort analysis are applied to the 2002 EDHS birth histories. Multivariate statistical models are used to examine the fertility trend in more depth and to assess whether the fertility decline is due to changes in spacing of births, changes in age at marriage/marital status, cessation of further childbearing, or changes induced by socio-economic factors. It also assesses whether the border conflict alone accounts for the onset and reduction in fertility as Blanc (2004) argued, or if other factors as well have at least partially accounted for the decline.

\section{DATA AND METHOD}

The major source of data for this study is the 2002 EDHS. For comparison purposes, data from the 1995 EDHS was also used. The details of the surveys are described elsewhere (NSEO and ORC Macro, 1997, 2003).

To examine whether the fertility decline is conflict-led or due to changes in other fertility determinants, several methods were employed, including trend analysis of age- and parity-specific fertility, cohort analysis, and multivariate statistical modeling. In the trend analysis, annual TFRs and age- and parity- specific rates were estimated and plotted over a period of ten years before the survey (i.e., about seven years before and three years after the conflict started) in order to assess the timing of the fertility decline. Here, the main issue is that if the decline is conflict-led, then fertility change should follow rather than precede the conflict. The purpose of including age- and 
parity-specific estimates in addition to the summary measure (TFR) is mainly to explore the structure of the decline in more detail. By plotting such annual fertility estimates it is possible to examine whether the decline in different subgroups began before or after 1998, which is the year of the eruption of the border conflict.

To ascertain further evidence of the decline, a multivariate analysis of birth histories is employed. The specific model used is the Cox regression method. This method is preferred because it accurately handles the timing of birth events. The dependent variable is whether or not a woman experienced a live birth during the interval that is studied and the timing of that event. The independent variables include calendar period, parity, spacing of births, age at first marriage/marital status, region, ruralurban residence, and woman's education. Since it is difficult to identify specific factors that measure the conflict or link the border conflict directly with fertility, the impact of the conflict is measured in relation to historical calendar period. The focus is on how fertility changed during the conflict period in comparison to pre-conflict periods. The variable region also serves as a test criteria for the impact of the border conflict: if the conflict is responsible for initiating the fertility decline, then this decline should be most marked among populations with the more severe experience of conflict. Since two regions, Southern and Gash Barka, were the hardest hit, one would expect a stronger response in these two regions. Marital status and age at marriage are used to examine whether changes in age at marriage has an effect on the decline. Birth order and age of mother at birth of the previous child are included in multivariate analysis in order to examine which birth orders and ages of mother have been most responsive for the decline.

\section{REVIEW OF POSSIBLE DETERMINANTS OF FERTILITY IN ERITREA}

Fertility levels depend on a variety of factors, usually grouped into proximate and distant (socio-economic, environmental, and cultural) determinants of fertility (Davis and Blake, 1956). Bongaarts'(1978) framework indicates that the distant factors must operate through the more basic proximate determinants, which in turn influence the risk of childbearing. According to Bongaarts and Potter (1983), the main proximate variables that explain most of the observed differences in fertility between populations are the proportion of women married, the practice of contraceptive 
methods, the prevalence of induced abortion, and the duration of the period of postpartum insusceptibility. In this section, we evaluate whether there has been a change in the proximate determinants of fertility indicated above, and in some demographic and socio-economic factors, particularly child mortality, birth spacing, and education of women in Eritrea. Due to lack of data it is difficult to evaluate whether other socio-economic factors, for example employment status of women, have helped to trigger the rapid decline in fertility in Eritrea. This section also assesses briefly the border conflict and its impact on the social, economic and demographic environment of the country. We begin our examination by analyzing the proximate determinants of fertility.

\subsection{Proximate Determinants of Fertility}

Age at first marriage has been recognized as a crucial determinant of fertility because it marks the beginning of exposure to the risk of childbearing in societies where premarital sex is uncommon and where there is little deliberate effort to control fertility (Blanc and Rutenberg, 1990). Rising age at first marriage has a lowering effect on the level of fertility (Hinde and Mturi, 2000; Odimegwu, 1996). However, in some subSaharan African countries (Hinde and Mturi, 2000; Njogu and Martin, 1991; Innocent 2001), the effect of changes in nuptiality on overall fertility is not clear because of substantial fertility among never-married women.

In countries such as Eritrea, where pre-marital fertility is uncommon or very low, delays in marriage can cause a reduction in the number of women under risk of childbearing. In Eritrea, there are some indications of recent delays in age at first marriage. The overall proportion of never-married women aged 15-49 increased from $20 \%$ in 1995 to $24 \%$ in 2002. It increased in almost all age groups over this time. In 1995, for example, 62\% of women aged 15-19 were never married, about six years later this figure had risen to $69 \%$. Among women aged 20-24, $22 \%$ had not yet married in 1995 compared with $27 \%$ in 2002 . The trend in age at first marriage can also be assessed by computing the median age at marriage. Overall, the median age at first marriage for women aged 20-49 is estimated to be 16.7 and 18.1 for the 1995 and 2002 surveys respectively, suggesting an increase of more than one year between the 
two surveys. From these figures, one may expect that delayed age at marriage may have contributed to the recent fertility decline in Eritrea.

Some studies on fertility decline in sub-Saharan Africa (e.g., Caldwell et al., 1992; Njogu and Martin, 1991) show that past declines were predominantly due to increased contraceptive use. In Eritrea, contraceptive use is very low and has barely increased since 1995. According to the two EDHS reports, use of contraception among currently married women of reproductive age has remained constant at $8 \%$. This suggests that contraception cannot be a good contributor to the observed recent fertility decline.

In Eritrea, breastfeeding is almost universal and long. The median duration of breastfeeding has remained constant at 22 months since 1995 (NSEO \& ORC MACRO, 2003). Women are insusceptible to another conception if they are still amenorrhoeic (which is primarily determined by the length and intensity of breastfeeding) and/or are abstaining from sexual relations. Using the 1997 DHS data of Mozambique, Arnaldo (2004) found that long duration of breastfeeding combined with postpartum sexual abstinence gave a non-susceptible period of 20.4 months. This suggests that in societies where there is very little use of contraceptives, breastfeeding, sometimes in conjunction with postpartum sexual abstinence, is important as a method of birth spacing. In 2002, the median duration of amenorrhoea, sexual abstinence, and insusceptibility were, on average, 13.5, 3.0 and 14.6 months, respectively, whereas the corresponding figures in 1995 were 14.2, 2.7 and 16.6 months, respectively (NSEO and ORC Macro, 2003). It appears that the median duration of insusceptibility of 2002 is shorter by two months than that from 1995. Changes in the duration of postpartum insusceptibility are, therefore, not likely to be an important factor in the recent fertility decline.

As in most other African countries, statistics on abortion in Eritrea are scarce and unreliable because abortion is illegal unless it is intended to save the mother's life. Some information on abortion can be obtained from women who were admitted to hospitals for post-abortion complications, but such data are too small to be used as indicators at the national level. Thus, it is difficult to make an evaluation or analysis of the contribution of abortion to the fertility decline in Eritrea. But, it is not likely that this factor could have had any major impact on aggregate fertility trends. 


\subsection{Socio-Demographic Situation}

Eritrea lies in the northeastern region of Africa; fertility is still high in most countries of the region - Sudan, Djibouti, Ethiopia, and Somalia - but in Kenya fertility decline has been convincingly documented. Eritrea is a small country with a land area of about 125,000 square kilometers and is divided into six administrative regions. The Southern and Central regions are predominantly Christian and agricultural, whereas the Southern Red Sea, Anseba, Northern Red Sea, and Gash Barka regions are predominantly Muslim and pastoral. The Southern and Gash Barka regions were most affected by the border conflict with Ethiopia.

The population size of Eritrea is not known precisely because no population census has yet been conducted. However, extrapolations based on the local government's counts indicate that the population size of Eritrea is around 3.2 million. Four out of five people in Eritrea live in rural areas, but the urban population has been growing rapidly since the late 1990s, being largely boosted by Eritrean deportees and Ethiopians of Eritrean origin from Ethiopia, and refugees returning from the Sudan. Evidence from the EDHS indicates that the urban population has increased from $27 \%$ in 1995 to 38\% in 2002 (NSEO and ORC Macro, 1997, 2003). Overcrowded urban conditions have led to housing shortages in most urban areas. Such a shortage of adequate housing may delay births and encourage fertility limitation.

In macroeconomic terms, Eritrea is among the poorest sub-Saharan African countries, with an annual income per capita of US\$190. However, caution should be exercised in interpreting Eritrea's level of national income: the thirty years war for liberation (1961-1991) and the border war of 1998-2000 have seriously devastated its economy. Despite this, its infant and childhood mortality are low compared to some countries in northeast Africa which have enjoyed greater political stability than Eritrea. Infant mortality in Eritrea is 48 per 1000 live births, while the corresponding figure in the Sudan is 70, in Djibouti 117 and in Kenya 66 (Population Reference Bureau, 2003). Moreover, some progress has been made since independence in enrolment rates in primary and secondary education and in health services. 
Interactions between child mortality and fertility play a central role in explaining demographic transitions (Legrand and Phillips, 1996). Although there is no general level of child mortality which leads to a fertility decline when it is reached, there is a general consensus that a decline in child mortality is normally followed by a decline in fertility. In Eritrea, infant mortality declined from 72 to 48 per 1000 live births between 1995 and 2002 (NSEO and ORC Macro, 1997, 2003). While beyond our expectations, this decline in infant mortality is by no means implausible, despite the border conflict and economic crisis during 1998-2000. It could be that earlier developments in health, education, and other social services have made possible the change in child mortality. Thus, the decline in infant mortality which started in the early 1990s (Woldemicael, 1999) is likely to affect fertility. It is possible that Eritrean women are more likely to want fewer children if they have not experienced child loss than if they had such an experience.

Previous studies (e.g., Njogu and Martin, 1991; Rodriguez et al., 1984; Nair, 1996) show that the likelihood of bearing another child is also associated with the length of the preceding birth interval. According to these authors a longer previous birth interval (more than 24 months) is associated with a lower probability of a further birth. A comparison of the 1995 and 2002 EDHS data shows that the median birth interval in 2002 is two months longer than the median birth interval in 1995 (NSEO and ORC Macro, 1997, 2003). Such an increase in the length of birth interval is likely to have some further impacts on the recent decline of fertility.

\subsection{War and Economic Instability in Eritrea}

Available literature on the impact of crises on demographic events indicates that war and economic crises can lead to low aspirations and a crisis-led fertility decline (Hobcraft, 1996; Eloundou-Enyegue, et al., 2000). For example, Hobcraft's (1996) study of pre-industrial Europe show that the number of births decreases during war and/or economic crises with a rebound in post-crisis periods. Some studies in less developed countries (e.g., Palloni et al., 1996; Dyson, 1991; Ashton et al., 1984; Lindstrom and Betemariam, 1999) indicate that war and economic crises have led to famine, psychological stress, nutritional deficiency and lack of motivation of a population to reproduce. For example, the study by Lindstrom and Betemariam 
(1999) using data from the 1990 National Family and Fertility Survey of Ethiopia indicates significant short-term decline in annual marital fertility probabilities during years of major political instabilities and famine in that country. Eloundou-Enyegue et al. (2000) found a $20 \%$ fertility decline in Cameroon which was largely confined to urban areas and this decline was consistent with the country's economic downturn in 1987. However, the evidence on the impact of crisis on fertility is not conclusive. For example, in Lebanon, no significant impact of the civil war on fertility decline was found (Khlat et al., 1997; Kulezycki and Saxena, 2000).

In the past three to four decades, Eritrea has been in a state of war with Ethiopia, although the intensity of hostilities varied over time. Only in recent years has Eritrea lived through a relative peace (1992 through mid-1998). During the 1970s and 1980s, Eritrea suffered human tragedy and socio-economic devastation of immense proportions because of the thirty years of war for liberation (1961-1991). Tens of thousands of people were killed; a large number of vulnerable population groups were created and many educated and skilled Eritreans were forced to migrate to other countries. The severity of the war of liberation resulted in profound damage to the national economy and touched every sector and ministry of the country. Moreover, this war had far-reaching repercussions on the country's demographic situation. For example, infant mortality was very high during the war period (about 80 per 1000 live births) and expectation of life at birth was around 50 years. The war also inhibited nuptiality and fertility because a large number of unmarried young men emigrated and were displaced, resulting in a distortion of the population pyramid and skewed sex ratios in the population of reproductive ages (see Woldemicael, 1999). In general, prolonged war and military tensions with Ethiopia in combination with cycles of drought and lingering poverty has made life in Eritrea very tough during the past decades.

The attainment of Eritrean independence in 1991 fostered high expectations that it would create a new opportunity for socio-economic development. As anticipated, progress was made between 1992 and 1997. The political stability and peace enjoyed by Eritrea during 1992-1997 enabled the authorities to concentrate on designing and implementing successful programs in areas such as in economy, health, education, and agriculture. Between 1993 and 1997, Eritrea's real GDP grew at an average 
annual rate of $7 \%$. Total government expenditure grew by $79 \%$ during this period. There was also major investment in extending health care services and education. As a result, infant and child mortality rates sharply declined, immunization coverage was expanded, and polio came close to being eliminated. The primary school gross enrolment ratio increased from 36\% in 1992 to 52\% in 1997 (Ministry of Education, 2002).

Unfortunately, Eritrea's initial promising socio-economic growth was disrupted by the border conflict with Ethiopia that started in May 1998 and resulted in a war that continued until 2000. This unexpected conflict reversed much of the progress that Eritrea made during 1992-1997. The war not only caused loss of human life, displacement of nearly one-third of the total population (about one million people), and huge damage to physical infrastructure, but also reversed much of the progress in socio-economic trends of the pre-conflict post-independence period (UN, 2002). For instance, the conflict resulted in a decline in real GDP growth from about $8 \%$ annually during $1993-1997$ to $4 \%$ in $1998,1 \%$ in 1999, and a negative growth of $8 \%$ in 2000; inflation rose from an average of 6\% during 1994-1997 to $27 \%$ in 2000; and the fiscal deficit increased from 6\% of GDP in 1997 to $48 \%$ of GDP in 2000 (UN, 2002). Prices of food and other commodities rose rapidly in 1998 and continued to rise throughout the war period (1999-01). In addition, the border conflict resulted in the military mobilization of all Eritreans, mostly males aged 18-40 years. It is likely that such mobilization decreased the proportion of married couples living together: a comparison of the proportion of married women residing with their husbands at the time of the 1995 and 2002 EDHS surveys shows a significant decline in all age groups (see Table 1), particularly among younger age groups in 2002. For example, only three in ten married women age 15-19 were living with their husbands in 2002, while the corresponding figure was six in ten in 1995. One would expect that separation of couples might have reduced married women's susceptibility to become pregnant; Lindstrom and Berhanu (1999) found that spousal separation was the main mechanism by which the civil war affected fertility in Ethiopia. 
Table 1: Percent ever married and percent of married women residing with husband, by age

\begin{tabular}{lcrcr}
\hline Current & \multicolumn{2}{c}{ Ever married } & \multicolumn{2}{c}{ Residing with husband } \\
Age & 1995 & 2002 & 1995 & 2002 \\
\hline $15-19$ & 37.6 & 31.0 & 60.4 & 30.5 \\
$20-24$ & 78.1 & 72.7 & 74.4 & 42.1 \\
$25-29$ & 92.1 & 88.5 & 79.1 & 48.9 \\
$30-34$ & 95.8 & 95.4 & 84.0 & 60.6 \\
$35-39$ & 98.2 & 97.8 & 88.4 & 72.4 \\
$40-44$ & 97.3 & 99.0 & 89.0 & 78.9 \\
$45-49$ & 98.1 & 99.2 & 90.6 & 88.0 \\
Total & 80.0 & 76.7 & 80.9 & 58.5 \\
\hline
\end{tabular}

These figures are calculated from the 1995 and 2002 EDHS data files.

\section{RESULTS FROM TREND ANALYSIS OF FERTILITY RATES}

\subsection{Trends in TFR and Age-Specific Fertility Rates from 1992 to 2001}

We begin our investigation of recent trends in Eritrean fertility by estimating aggregate measures of fertility (TFRs) and age- and parity-specific fertility rates over the ten years before the survey. In later sections, relative risks from multivariate regression analyses are presented.

According to the NSEO and ORC Macro (2003) estimates, TFR declined by $21 \%$ from mid-1990s to 2002. Blanc (2004) found a decline of about $31 \%$ during the same period. To assess if such a decline was consistent throughout the period considered, a trend analysis is made here to generate estimates of total and age- specific fertility rates for the ten years before the 2002 EDHS survey. Figure 1 shows annual TFRs for the period 1992-2001. The TFR increased from 5.8 in 1992 to 6.6 in 1995, with a subsequent gradual decline from 1996 to 1999. After 1999, a consistent and rapid decline from 5.4 children per woman in 1999 to 4.3 children per woman in 2001 occurred. Our estimates of TFR and the relative decline (about 34\%) from 1995 to 2001 are almost consistent with Blanc's (2004) estimates. However, the evidence presented here does not necessarily support Blanc's thesis that the decline is a conflict-initiated decline and the fact that the decline started in 1996, well before the conflict, rather corroborates our counter-argument. The border conflict appears to account partially for the rapid fertility decline after 1999. According to Lindstrom and Berhanu (1999), war and economic crisis may result in significantly lower fertility. 
Agadjanian and Prata (2002) also found that war had a negative effect on fertility in Angola.

Figure 1 about here

Figures 2, 3, 4 and 5 present age- and parity-specific fertility rates for successive single calendar years before the survey for the country as a whole (age- and parityspecific rates) as well as for rural and urban areas (age-specific rates). The agespecific estimates for the whole country (Figure 2) support the above observation that a peak occurred in 1995 followed by a downward trend in fertility until the recent past with an accelerated decline after 1999. The estimates for the rural areas (Figure 4) follow the same trend as for the whole country. As $80 \%$ of the population live in rural areas, the decline in fertility in these areas had a decisive effect for the national level. The decline occurred at all reproductive ages, but was slightly stronger among older women. Figure 5 demonstrates that fertility rates of mothers decreased across all birth orders from mid-1990s and onwards, but the decline seems to be relatively greater among higher birth orders. Such a trend appears to be consistent with the patterns of fertility transition found in other sub-Saharan African countries in which the fertility decline is more pronounced at older ages and higher parities (van de Walle and Foster, 1990). For the urban areas (Figure 4), the rates show no consistent decline for the younger ages (15-24 years), but there is a clear declining trend for ages 25-34 after 1996.

Figures 2, 3, 4, and 5 about here

In summary, although it is difficult to establish a direct causal link between political change and fertility in Eritrea, the findings from the trend analysis offer some evidence on how the changes in fertility coincide with three major historical events in Eritrea: the end of the thirty years struggle for independence in 1991, the subsequent political stability and peace in 1992-1997, and the more recent border conflict with Ethiopia (mid-1998-2000). The slightly lower fertility at the beginning of our study period may be seen as a response to economic decline and political instability caused by the war for independence (1961-1991). The demographic effects of conscription of young men, postponement of marriages and births, separation of married couples, migration and displacement during the preceding period can only be guessed, but it is 
clear that these factors can reduce fertility. The increase in fertility during 1993-1995 could be a reflection of the boom in marriages and of births that were postponed during the war for liberation. This is consistent with some studies of pre-industrial Europe (Hobcraft, 1996) which indicate a sharp decline of fertility during war years with a rebound in post-war periods. The following decline in fertility is perhaps due to a weakening of the child loss motivation for high fertility because of higher proportions of children surviving during the peace period. It may reflect improvements in women's education, health care services and the related reduction in infant and child mortality and it is also possible that delayed marriage has contributed to the fertility decline. A preliminary multivariate analysis on first-marriage risks shows that the risk of marriage is significantly lower in the most recent period (not presented here). Finally, it is important to note that the fertility decline after 1999 is very swift and it is implausible to attribute it solely to improvements in child mortality and in socio-economic conditions or to increased age at marriage. It is likely that the border conflict has accelerated the decline.

Another way of examining fertility trends is by tabulating cumulative fertility for different age groups for successive five-year periods before the survey. Such cohortperiod specific fertility rates are shown in Table 2.

\subsection{Cohort and Period Fertility}

Table 2 presents cumulated age-specific fertility rates from the cohort analysis for three successive five-year periods before the survey. As can be seen from this table, the fertility decline is only apparent in the five-year periods immediately prior to the survey. The preceding rise in fertility is consistent with the trend revealed by the total and age-specific fertility rates presented above. 
Table 2: Cumulative cohort-period age-specific fertility, Eritrea

\begin{tabular}{lccc}
\hline Age & \multicolumn{3}{c}{$\begin{array}{c}\text { Calendar Period } \\
1992-96\end{array}$} \\
\hline $15-19$ & $0.507-01$ & 0.61 & 0.55 \\
$20-24$ & 1.53 & 1.87 & 1.82 \\
$25-29$ & 2.70 & 3.41 & 3.32 \\
$30-34$ & 3.84 & 4.89 & 4.84 \\
$35-39$ & 4.80 & 6.16 & \\
$40-44$ & 5.34 & & \\
Ratios* of cumulated cohort-period fertility & \\
Age & & & \\
$15-19$ & 0.81 & 1.11 & \\
$20-24$ & 0.81 & 1.03 & \\
$25-29$ & 0.79 & 1.03 & \\
$30-34$ & 0.78 & 1.01 & \\
$35-39$ & 0.77 & & \\
$40-44$ & & & \\
& & & \\
\hline
\end{tabular}

These figures are calculated from the 2002 EDHS data files

* Obtained by dividing the cumulative fertility for the later period by that for the preceding period

\section{MULTIVARIATE ANALYSIS RESULTS}

In the above analyses aggregate fertility (TFR) and nonstandardized age- and parityspecific period rates were used to assess trends. But, such measures do not capture the impact of changes in birth spacing, age at marriage, and other reproductive behavioral factors on family size limitation. In this section, multivariate regression models are used to perform an in-depth investigation of the fertility decline and to examine the possible contribution of various factors to the decline. The analysis and interpretation of the association between explanatory variables and fertility is facilitated by estimation of separate models for first and higher order births. We expect that some variables have different impacts on fertility at different birth orders. For example, age at first marriage and marital status may be more important for first births (onset of reproduction) than for fertility at higher birth orders. Variables such as age of woman at birth of previous child, birth order, and spacing of births are only applicable for higher parities. Childhood residence, region of residence, and education of woman are used as control variables and are included in both first and higher order birth models. Calendar period, which is the key factor in this study, is used in all analyses. It is used as a time-varying covariate and is measured by a set of dummy variables, defined as: 
before 1987, 1987-91, 1992-94, 1995-98, 1999-00 and 2001-02. This grouping reflects the past political and economic situation of the country. The period before 1992 refers to the time of war for independence, the period between 1992 and 1998 indicates the post independence period of peacefulness and stability and the last two categories (1999-00 and 2001-02) were periods of border conflict and economic crisis.

Tables 3 and 4 present the results from multivariate analysis of first births of all women and of married women only, respectively. The results clearly indicate that first birth fertility was highest during the period when Eritrea enjoyed greater political stability and economic improvements (1995-1998). Rural-urban differentials (Model 1, Table 3) indicate that first birth fertility is lower in urban than in rural areas. As expected, fertility is higher among married than among never married women. However, controlling for marital status (Model 2, Table 3) reversed the rural-urban differential in first birth fertility. This suggests that rural-urban differential in first birth fertility is not due to rural-urban residence per se, but to differences in marital status between rural and urban areas. In the urban areas women marry later but as soon as they marry they have their first birth. The effect of calendar period remains largely consistent and statistically significant even with the addition of marital status (Model 2). An interaction between rural-urban childhood residence and calendar period did not show any rural-urban differentials by period (not presented here). Model 3 shows no significant difference in first birth fertility among the different regions, except for the Southern region where the propensity to have a first birth is slightly higher than in the other regions. During the border conflict, two regions, Gash Barka and Southern, were more affected regions than other regions of the country. Thus, in order to assess whether the border conflict had different effects on the fertility of different regions, an interaction model between calendar period and region was run (not presented here). However, no regional differences in fertility trends of first births were found. 
Table 3: Relative risks of first birth fertility associated with selected socio-demographic variables

\begin{tabular}{|c|c|c|c|}
\hline & Model 1 & Model 2 & Model 3 \\
\hline \multicolumn{4}{|l|}{$\frac{v^{\text {arriable }}}{\text { Period }^{\mathbf{t}}}$} \\
\hline$<1987$ & $0.64 * * *$ & $0.58^{* * *}$ & $0.58 * * *$ \\
\hline $1987-91$ & $0.88 * * *$ & $0.83 * * *$ & $0.82 * * *$ \\
\hline 1992-94 & $0.75^{* * *}$ & $0.75^{* * *}$ & $0.74 * * *$ \\
\hline 1995-98 & 1 & 1 & 1 \\
\hline 1999-00 & $0.73 * * *$ & $0.78^{* * *}$ & $0.79 * * *$ \\
\hline 2001-02 & $0.67 * * *$ & $0.71 * * *$ & $0.71 * * *$ \\
\hline \multicolumn{4}{|l|}{ Childhood residence } \\
\hline Rural & 1 & 1 & 1 \\
\hline Urban & $0.62 * * *$ & $1.14 * * *$ & $1.12 * *$ \\
\hline \multicolumn{4}{|l|}{ Marital status ${ }^{t}$} \\
\hline Married & - & 1 & 1 \\
\hline Never married & - & $0.05^{* * *}$ & $0.05 * * *$ \\
\hline \multicolumn{4}{|l|}{ Region } \\
\hline Southern Red Sea & - & - & 1 \\
\hline Maekel & - & - & 1.06 \\
\hline Northern Red Sea & - & - & 0.96 \\
\hline Anseba & - & - & 1.02 \\
\hline Gash Barka & - & - & 0.94 \\
\hline Southern & - & - & $1.13 * *$ \\
\hline Change in degrees of & df) & 1 & 5 \\
\hline Change in model stat & tistic) 185.17 & 7150.14 & 25.49 \\
\hline
\end{tabular}

$*$ Factor level significant at $<10 \%, \quad * *$ significant at $<5 \% \quad * * *$ significant at $<1 \%$
${ }^{\mathrm{t}}$ Time varying covariates

Table 4 considers only married women. The main purpose of this table is to check whether delayed age at first marriage had a significant effect on the recent decline in first birth fertility of childless women. It is clear from Table 4 that urban residence during childhood does not reduce first birth fertility. Contrary to literature and expectations, first birth fertility is higher among women who married at older ages than those married at young ages. Evidently, those who marry late give their first birth immediately after marriage while those who marry very early delay their first birth. In Eritrea, where most marriages start very early, women often continue to live in their parents' home for several years even after getting married. During that period they are unlikely to become pregnant because of sexual abstinence or biological immaturity. The addition of age at first marriage in the models of first births does not result in any alteration of the period-fertility relationship.

A higher level of women's education is believed to be associated with lower level of fertility (e.g., UN, 1987; Freedman, et al., 1988). This is because education leads to a rise in age at first marriage and to enhancement of women's ability to make reproductive choices, such as greater use of contraception and postponement of 
childbearing, and to achieve low family size desires (Knodel and Pitaktepsombati, 1973; Martin and Juarez, 1995). However, unlike previous studies in other countries, education of women in Eritrea shows a significant positive relationship with fertility of married childless women. This may suggest that once educated women are married, they rapidly enter into motherhood.

Table 4: Relative risks of first birth fertility of married women associated with selected sociodemographic variables

\begin{tabular}{|c|c|c|c|c|}
\hline Variable & Model 1 & Model 2 & Model 3 & Model 4 \\
\hline \multicolumn{5}{|l|}{ Period $^{t}$} \\
\hline$<1987$ & $0.53 * * *$ & $0.57 * * *$ & $0.58 * * *$ & $0.57 * * *$ \\
\hline $1987-91$ & $0.79 * * *$ & $0.82 * * *$ & $0.73 * * *$ & $0.83 * * *$ \\
\hline $1992-94$ & $0.74 * * *$ & $0.75 * * *$ & $0.76 * * *$ & $0.76 * * *$ \\
\hline $1995-98$ & 1 & 1 & 1 & 1 \\
\hline 1999-00 & $0.81 * * *$ & $0.80 * * *$ & $0.80 * * *$ & $0.80 * * *$ \\
\hline 2001-02 & $0.73 * * *$ & $0.72 * * *$ & $0.71 * * *$ & $0.71 * * *$ \\
\hline \multicolumn{5}{|l|}{ Childhood residence } \\
\hline Rural & 1 & 1 & 1 & 1 \\
\hline Urban & $1.26 * * *$ & $1.19 * * *$ & 1.08 & 1.08 \\
\hline \multicolumn{5}{|l|}{ Age at $1^{\text {st }}$ marriage } \\
\hline$<16$ & - & 1 & 1 & 1 \\
\hline $16-19$ & - & $1.38 * * *$ & $1.38 * * *$ & $1.38 * * *$ \\
\hline $20+$ & - & $1.55 * * *$ & $1.55 * * *$ & $1.55 * * *$ \\
\hline \multicolumn{5}{|l|}{ Education of mother } \\
\hline No education & - & - & 1 & 1 \\
\hline Primary & - & - & $1.16^{* * *}$ & $1.14 * * *$ \\
\hline Secondary or higher & - & - & $1.20 * * *$ & $1.18 * * *$ \\
\hline \multicolumn{5}{|l|}{ Region } \\
\hline Southern Red Sea & - & - & - & 1 \\
\hline Maekel & - & - & - & 1.01 \\
\hline Northern Red Sea & - & - & - & 1.01 \\
\hline Anseba & - & - & - & 1.07 \\
\hline Gash Barka & - & - & - & 0.92 \\
\hline Southern & - & - & - & 1.07 \\
\hline Change in degrees of $\mathrm{fr}$ & 1 & 2 & 2 & 5 \\
\hline Change in model statist & istic) 33.37 & 177.58 & 20.45 & 25.40 \\
\hline
\end{tabular}

Table 5 displays the multivariate analysis of second and higher order births. Consistent with the previous trend analysis, the results in this table show that fertility is lowest during 1999-2002. The addition of other variables makes no significant difference to the period-fertility relationship. The results show that fertility is reduced among women older than 35 years. A reduction in fertility is also observed at the higher birth orders (Models 4 and 5). The effects of rural-urban childhood residence and education of women is in the expected direction and statistically significant, where fertility is lower among women with some education and who lived in urban 
areas during childhood. The effect of previous birth interval is clear and significant, where longer birth intervals are associated with lower fertility.

Table 5: Relative risks of fertility of (higher order births) associated with selected sociodemographic variables

\begin{tabular}{|c|c|c|c|c|c|}
\hline Variable & Model 1 & Model 2 & Model 3 & Model 4 & Model 5 \\
\hline \multicolumn{6}{|l|}{ Period $^{t}$} \\
\hline$<1987$ & 0.97 & 0.96 & $0.94 * *$ & $0.95 * *$ & $0.95^{* *}$ \\
\hline $1987-91$ & $1.19 * * *$ & $1.19 * * *$ & $1.17 * * *$ & $1.17 * * *$ & $1.17 * * *$ \\
\hline $1992-94$ & $1.07 * * *$ & $1.06^{* *}$ & $1.05^{* *}$ & $1.05^{* *}$ & $1.05^{* *}$ \\
\hline $1995-98$ & 1 & 1 & 1 & 1 & 1 \\
\hline 1999-00 & $0.75 * * *$ & $0.75^{* * *}$ & $0.75 * * *$ & $0.75 * * *$ & $0.75 * * *$ \\
\hline 2001-02 & $0.66 * * *$ & $0.66^{* * *}$ & $0.66 * * *$ & $0.67 * * *$ & $0.67 * * *$ \\
\hline \multicolumn{6}{|l|}{ Age of mother } \\
\hline$<20$ & 1 & 1 & 1 & 1 & 1 \\
\hline $20-24$ & 1.03 & 1.04 & 1.04 & $1.09 * * *$ & $1.08 * * *$ \\
\hline $25-29$ & 1.03 & 1.04 & 1.03 & $1.11 * * *$ & $1.11 * * *$ \\
\hline $30-34$ & $0.94 * *$ & $0.95 *$ & $0.94 * *$ & 1.03 & 1.02 \\
\hline $35-39$ & $0.78 * * *$ & $0.79 * * *$ & $0.79 * * *$ & $0.87 * * *$ & $0.87 * * *$ \\
\hline $40-49$ & $0.58 * * *$ & $0.57 * * *$ & $0.56 * * *$ & $0.63 * * *$ & $0.62 * * *$ \\
\hline \multicolumn{6}{|l|}{ Birth order } \\
\hline $2-3$ & 1 & 1 & 1 & 1 & 1 \\
\hline $4-5$ & 1.02 & 1.01 & 0.99 & $0.95 * * *$ & $0.95 * *$ \\
\hline $6-7$ & 1.01 & 0.99 & 0.97 & $0.91 * * *$ & $0.91 * * *$ \\
\hline $8+$ & $0.89 * * *$ & $0.87 * * *$ & $0.85^{* * *}$ & $0.77 * * *$ & $0.78 * * *$ \\
\hline \multicolumn{6}{|l|}{ Childhood residence } \\
\hline Rural & - & 1 & 1 & 1 & 1 \\
\hline Urban & - & $0.78 * * *$ & $0.93 * * *$ & $0.92 * * *$ & $0.92 * * *$ \\
\hline \multicolumn{6}{|l|}{ Education of mother } \\
\hline No education & - & - & 1 & 1 & 1 \\
\hline Primary & - & - & $0.85^{* * *}$ & $0.86 * * *$ & $0.85 * * *$ \\
\hline Secondary or higher & - & - & $0.66 * * *$ & $0.66 * * *$ & $0.66 * * *$ \\
\hline \multicolumn{6}{|l|}{ Previous birth interval } \\
\hline$<18$ & - & - & - & 1 & 1 \\
\hline $18-23$ & - & - & - & $0.93 * * *$ & $0.93 * * *$ \\
\hline $24-35$ & - & - & - & $0.89 * * *$ & $0.89 * * *$ \\
\hline $36-47$ & - & - & - & $0.78 * * *$ & $0.78 * * *$ \\
\hline $48+$ & - & - & - & $0.72 * * *$ & $0.72 * * *$ \\
\hline \multicolumn{6}{|l|}{ Region } \\
\hline Southern Red Sea & - & - & - & - & 1 \\
\hline Central & - & - & - & - & $0.95 *$ \\
\hline Northern Red Sea & - & - & - & - & $0.95 *$ \\
\hline Anseba & - & - & - & - & 1.02 \\
\hline Gash Barka & - & - & - & - & $0.93 * * *$ \\
\hline Southern & - & - & - & - & 1.01 \\
\hline $\begin{array}{l}\text { Change in degrees } \\
\text { of freedom ( } \Delta \mathrm{df}) \\
\text { Change in model }\end{array}$ & 3 & 1 & 2 & 4 & 5 \\
\hline $\operatorname{statistic}\left(\Delta \chi^{2}\right.$ statistic $)$ & 16.88 & 98.14 & 134.88 & 182.03 & 23.10 \\
\hline
\end{tabular}

\footnotetext{
$*$ Factor level significant at $<10 \%, \quad * *$ significant at $<5 \%, \quad * * *$ significant at $<1 \%$

t Time varying covariate
} 
In this study, all possible interactions were explored, and interactions of calendar period with age of mother at the birth of the previous child, with birth order, and with region were found to be significant. Summaries of the interaction terms are presented in Tables 6, 7 and 8. The results indicate that fertility is much lower during the most recent period (1999-02) than the period before 1999 for all birth orders and age groups. However, the strongest decline is observed for birth orders four and above, and for mothers at higher ages. These findings seem to fit with the claim put forward by van de Walle and Foster (1990), that a decline of fertility in sub-Saharan Africa will be characterized by a concentration of declines among high parity and/or older women who have achieved or exceeded their desired family size. The findings also confirm the results found in some Latin American countries in the early 1960s where the decline was more pronounced among birth orders 4, 5 and 6 (Rodriguez and Hobcraft, 1980). In order to examine whether or not the effects of the border conflict were more pronounced in the regions with the more severe experience of the war, we estimated a further interaction model (Table 8). As indicated earlier, Southern and Gash Barka regions were expected to exhibit a greater fertility response, because these were the regions that suffered the most. The results reveal a consistent and significant fertility decline in all regions during 1999-2002, but no regional differential in fertility decline is observed.

One would expect that to some extent the recent fertility decline is due to the recent increase in the proportion of women not residing with their husbands. However, if separation of women from their spouses had been a major contributing factor to the recent fertility decline, one should have observed a stronger reduction in fertility among younger women (15-29 years) than among older women because the proportion of spousal separation is higher among the younger (see Table 1). The fact that such a pattern is not observed may imply that the contribution of spousal separation to the recent fertility decline is not entirely decisive and that the fertility decline is, at least to some extent, a lasting development rather than only a short-term impact induced by the war. 
Table 6: Interaction between calendar period and birth order in fertility ( $2^{\text {nd }}$ and higher birth orders)

\begin{tabular}{lllll}
\hline Period & $2-3$ & $\begin{array}{l}\text { Birth order } \\
4-5\end{array}$ & $6-7$ & $8+$ \\
\hline Before 1999 & 1 & 1 & 1 & 1 \\
$1999-2002$ & 0.73 & 0.64 & 0.64 & 0.65 \\
\hline $\begin{array}{l}\text { Change in degrees of freedom }(\Delta \text { df }) \\
\begin{array}{l}\text { Change in model statistic }\left(\Delta \chi^{2} \text { statistic }\right) \\
\text { p=0.000 }\end{array}\end{array}$ & $\begin{array}{l}9.78 \\
\end{array}$
\end{tabular}

Table 7: Interaction between calendar period and age of mother in fertility ( $2^{\text {nd }}$ and higher birth orders)

\begin{tabular}{lcccccc}
\hline Period & \multicolumn{1}{l}{ Age of mother } & 25-29 & $30-34$ & $35-39$ & $40-49$ \\
\hline Before 1999 & 1 & 1 & 1 & 1 & 1 & 1 \\
$1999-2002$ & 0.76 & 0.71 & 0.64 & 0.66 & 0.56 & 0.54 \\
\hline
\end{tabular}

Change in degrees of freedom $(\Delta \mathrm{df})$

5

Change in model statistic $\left(\Delta \chi^{2}\right.$ statistic $) \quad 24.75$

$\mathrm{p}=0.000$

Table 8: Interaction between calendar period and region in fertility ( $2^{\text {nd }}$ and higher birth orders)

\begin{tabular}{lcccccc}
\hline Period & Southern RS & Central & $\begin{array}{c}\text { Region } \\
\text { Northern RS }\end{array}$ & Anseba & GashB & Southern \\
\hline Before 1999 & 1 & 1 & 1 & 1 & 1 & 1 \\
$1999-2002$ & 0.57 & 0.68 & 0.71 & 0.72 & 0.67 & 0.70 \\
\hline
\end{tabular}

Change in degrees of freedom $(\Delta \mathrm{df})$

5

Change in model statistic $\left(\Delta \chi^{2}\right.$ statistic $) \quad 21.52$

$\mathrm{p}=0.000$

Note: In the interaction terms, period is collapsed into two categories because preliminary interaction results indicated that the relative risks for the period before 1999 were similar. 


\section{DISCUSSION AND CONCLUSION}

The findings of this study show a trend of fertility decline since the mid-1990s in Eritrea, with this decline occurring in all regions of the country. Total fertility declined from about 6.6 in 1994/95 to 4.4 children per woman in 2000/01, suggesting a decline of more than $30 \%$. The trend analysis showed that the decline was relatively slow (12\%) between 1995 and 1999, but very rapid (24\%) between 1999 and 2001 the peak years of the border conflict. Such accelerated decline between the later part of the 1990s and the beginning of this century was also observed in the multivariate analysis of parity-specific childbearing. The TFR estimates of the present study and the size of the relative decline are consistent with Blanc's study (2004), but the evidence here does not really support her explanation for the decline. According to Blanc (2004), the border war of mid-1998 to 2000 is the main driving force behind the decline. Blanc's study suggests that the decline is partly due to the delay in age at first marriage and largely to the reduction in the proportion of married women living with their husbands, which the author identified as an outcome of the border war. However, it is clear from the present study that the timing of the onset of the fertility decline is not consistent with this conflict-related hypothesis.

In this study, we argue that the border conflict alone cannot be the sole explanation for the onset of the recent fertility decline and that no single factor can explain it (Mason, 1997; Caldwell, 1997b). The fact that the decline started in 1996, well before the conflict (mid-1998), supports this argument. Interactions of calendar period with age of mother and with parity clearly showed that although the decline occurs at all ages and at all birth orders, it is stronger among higher order parities (4 or more) and older mothers (35 years and older). These are clear indications that an increasing number of Eritrean women have reached their desired family size after their fourth or fifth child and reduce their fertility. If the border conflict was indeed the only factor responsible for the onset of the transition, the decline should have been across all groups of childbearing ages and all birth orders. In fact, we expect the decline to have been larger among younger cohorts (15-29 years) than among older ones because the proportion of married women not living with their husbands was significantly larger among the younger women. The fact that the major fertility decline was among older women (35 or above) and at higher parities (4 or higher) further corroborates our 
argument that the decline indicates the onset of a long-term fertility transition which is mainly related to other factors such as improvements in child survival, health care facilities, and education, which pre-dated the conflict. Additionally, if the conflict had been the major contributor for the reduction, a stronger decline should have been observed in the two regions which were most affected by the fighting. Furthermore, in contrast to Blanc's findings, this study found no decisive impact of the delayed age at marriage on fertility. The present study instead indicates that the decline in marital fertility is the main contributor to the overall decline. The recent fertility decline is due mainly to changes in birth spacing and postponement of higher-order births or to limiting births. Taken together, the above findings support our argument that the border conflict cannot be the major factor responsible for the onset of the recent fertility decline in Eritrea.

However, although we cannot say that the reduction in fertility is primarily the outcome of the border war (or a sudden phenomenon), this does not mean we can conclude that the border conflict is neutral in effect and has no contribution to the recent fertility decline in Eritrea. In particular, the rapidity of the decline after 1999 is extraordinary. A decrease in fertility from 5.8 to 4.2 births per woman within that short period seems unlikely to be explained by such factors as improvement in child survival, the social and economic transformations that pre-dated the border war, or other conscious changes in timing and spacing of births. The border war must definitely have accelerated the decline. The impact of the war can probably be seen as being made up of various mechanisms. There could have been a largely unintentional limiting of births due to social and economic disruptions directly caused by the military mobilization, fighting, and internal displacement of people, all of which lead to limited exposure to pregnancy. Also, psychological stress associated with declines in nutritional status or standard of living is also likely to reduce fecundity and frequency of intercourse. In addition to unintended negative effects, the outbreak of war and economic crisis may have led to conscious adjustments in fertility behavior because couples are more likely to opt to avoid births during times of trouble (CEPED, 1998). 
To summarize, it is plausible to suggest that the recent fertility decline indicates the beginning of a long-term fertility transition fuelled by a temporary impact of the 1998-2000 border conflict and economic crisis associated with it.

The Eritrean case challenges some of the conventional beliefs that nuptiality delay and contraceptive use lead to fertility decline. There is a general consensus that fertility decline that has occurred among older women in most countries was achieved mostly through use of fertility control, while reductions in fertility among younger women were mainly achieved through postponement of marriage. The Eritrean case, however, does not provide strong evidence of the effect of fertility control or delayed marriage on the fertility decline.

Finally, given the present political and economic situation of the country, it seems difficult to predict the future course of fertility in Eritrea. However, on the basis of the present findings, fertility in Eritrea may continue to decline in the future, though the magnitude and nature may depend on socio-economic development and the political stability of the country. The slow decline observed from 1995 to 1999 is likely to be sustained in the future, assuming normal conditions in the country. If however, the border conflict (which is still unresolved) continues or fighting resumes, the decline may be further accelerated. Such a decline might be followed by a temporary recovery, but our main impression is nevertheless that the long-term development is set to be a reduced fertility in contemporary Eritrea.

\section{ACKNOWLEDGEMENTS}

This paper used the data collected by the National Statistics and Evaluation Office (NSEO) of Eritrea in collaboration with MACRO ORC Inc in 1995 and 2002. The computerized data files were provided by the NSEO. I am grateful for this support. The study was made while being a short-time research fellow at the Max Planck Institute for Demographic Research, Rostock, Germany during June-August 2004 and 2005. I would like to express my appreciation and gratitude to Prof. Jan M. Hoem for providing this opportunity. I would also like to thank Dr. Gunnar Andersson for helpful advice during the analysis and valuable comments on the final draft of the paper, and Dr. Andres Vikat who was very helpful in providing valuable advice and help, particularly for the trend analysis. 


\section{REFERENCES}

Agadjanian, V. and Prata, N. 2002. War, peace, and fertility in Angola. Demography 39: $215-231$.

Arnaldo, C. 2004. Regional fertility trends in Mozambique. Journal of Population Research 21: 177-197.

Ashton B., Hill K., Piazza A. and Zeitz R. 1984. Famine in China 1958-61. Population and Development Review 10: 613-645.

Blanc, A.K. and Rutenberg, N. 1990. Assessment of the quality of data at first sex, age at first marriage and age at first birth. Demographic and Health Surveys. In Assessment of DHS-I Data Quality. Institute for Resource Development. DHS Methodological Reports, no.1, Columbia, Maryland.

Blanc, A.K. 2004. The role of conflict in the rapid fertility decline in Eritrea and Prospects for the future. Studies in Family Planning 35: 236-245.

Bongaarts, J. and Potter, R.G. 1983. Fertility, Biology and Behavior: An Analysis of the Proximate Determinants. Academic Press. New York and London

Bongaarts, J. 1978. A Framework for analyzing the proximate determinants of fertility. Population and Development Review 4: 105-132.

Caldwell, J.C. and Caldwell, P. 2001. Regional paths to fertility transition. Journal of Population Research 18: 91-117.

Caldwell, J.C. 1997. The global fertility transition: The need for a unifying theory. Population and Development Review 23: 803-812.

Caldwell, J.C., Orubuloye, I.O. and Caldwell, P. 1992. Fertility decline in Africa: a new type of transition? Population and Development Review 18: 211-242.

CEPED, The French Center for Population and Development, 1997. Crisis and Demographic Transition in Africa. The CEPED NEWS, no. 2, pp. 1-5. Paris.

Davis K. and Blake J. 1956. Social Structure and Fertility: An Analytical Framework. Economic Development and Cultural Change 4: 211-235

Dyson T. 1991. On the demography of South Asian families. Population Studies 45: $5-26$. 
Eloundou-Enyegue, P, Stokes, C.S., and Cornwell, G.T. 2000. Are there crisis-led fertility declines? Evidence from central Cameroon. Population Research and Policy Review 19: 47-72.

Freedman R., Xiao X., Bohua L., Lavely W.R. 1988. Education and fertility in two Chinese provinces: 1967-70 to 1979-82. Asia Pacific Population Journal 3: 3-29.

Hinde, P.A. and Mturi, A.J. 2000. Recent trends in Tanzania fertility. Population Studies 54: 177-191.

Hobcraft, J. 1996. Fertility in England and Wales: A fifty-year perspective. Population Studies 50: 485-524.

Innocent N. 2001. Socio-economic factors associated with pre-marital childbearing and adolescents' age at first motherhood. Paper presented at the XXIV IUSSP General Population Conference, 18-24 August 2001. Salvador, Brazil.

Khlat M., Deeb M. and Courbage Y. 1997. Fertility Levels and Differentials in Beirut during wartime: An indirect estimation based on maternity registers. Population Studies 51: 85-92.

Kirk, D. and Pillet, B. 1998. Fertility levels, trends, and differentials in sub-Saharan Africa in the 1980s and 1990s. Studies in Family Planning 29:1-22.

Knodel J., Pitaktepsombati P. 1973. Thailand: Fertility and Family Planning among rural and urban women. Studies in Family Planning 4: 229-255.

Kulczycki, Andrzej and Prem C. Saxena 2000. New evidence on Fertility transition through wartime in Lebanon. Paper presented at the Population Association of America Annual Meeting, Los Angels, CA, 23-25 March 2000.

Legrand T.K. and Philiips J.F. 1996. The effect of fertility reductions on infant and child mortality: Evidence from Matlab in rural Bangladesh. Population Studies 50: 51-68.

Lindstrom, David P. and Betemariam Berhanu 1999. The impact of war, famine, and economic decline on marital fertility in Ethiopia. Demography 36: 247-261.

Luther, Norman, Y. and Pejaranonda 1991. The parity structure of fertility decline in Thailand, 1953-1979. Genus 47: 63-88.

Martin T., Juarez F. 1995. The impact of women's education on fertility in Latin Americo: Search for explanation. International Family Planning Perspective 21: $52-57$.

Mason, K.O. 1997. Explaining fertility transitions. Demography 34: 443-454. 
Ministry of Education 2002. Eritrea: Essential Education Indicators 2001/02, pp. 139. Ministry of Education. Asmara, Eritrea.

Mturi, A.J. and Hinde, P. A. 1994. Fertility decline in Tanzania. Journal of Biosocial Science 26: 529-538.

Nair, S.N. 1996. Determinants of birth intervals in Kerala: An application of Cox's hazard Model. Genus LII-n 3-4: 47-65.

NSEO (National Statistics and Evaluation Office) and ORC Macro 2003. Eritrea Demographic and Health Survey 2002. Calverton, Maryland, USA.

NSEO (National Statistics and Evaluation Office) and ORC Macro 1997. Eritrea Demographic and Health Survey 1995. Calverton, Maryland, USA.

Njogu W. and Martin T.C. 1991. Fertility decline in Kenya: The role of training and spacing of births, in IRD/Macro International, Inc. 1991, Proceedings of the Demographic and Health Surveys World Conference Vol. III. Washington, D.C. 1991, Columbia, Maryland.

Odimegwu, C.O. 1996. Understanding the proximate determinants of fertility of a Nigerian Ethnic group. Genus LII-n 3-4: 67-87.

Palloni A., Hill K. and Pinto Aguirre G. 1996. Economic Swings and Demographic Changes in the History of Latin America. Population Studies 50: 105-132.

Population Reference Bureau 2003. 2003 World Population Data Sheet of the Population Reference Bureau: Demographic Data and Estimates for the Countries and Region of the World. Washington. USA.

Rodriguez G. and Hobcraft J. 1980, Illustrative Analysis: Life Table Analysis of Birth Intervals in Colombia, WFS Scientific Report, no.16, Voorburg, International Statistical Institute.

Rodriguez, G., Hobcraft T., McDonald J., Menken J. and Trussell J. 1984. A comparative analysis of determinants of birth intervals. WFS Comparative Studies, 30. Voorburg, Netherlands: International Statistical Institute.

UN 1987. Fertility Behaviour in the context of development: Evidence from the World Fertility Survey. Population Studies 100 ST/ESA/SERA/100, United Nations, N.Y.

UN 2002. United Nations Development Assistance Framework (UNDAF) (20022006). Asmara, Eritrea 
Van de Walle E. and Foster A.D. 1990. Fertility decline in Africa, Assessment and prospects. World Bank Technical Paper no. 125. Africa Technical Department, The World Bank, Washington D.C..

Woldemicael, G. 1999. Infant and Child Mortality in Eritrea: Levels, Trends and Determinants. Doctoral Dissertation. Stockholm University. 

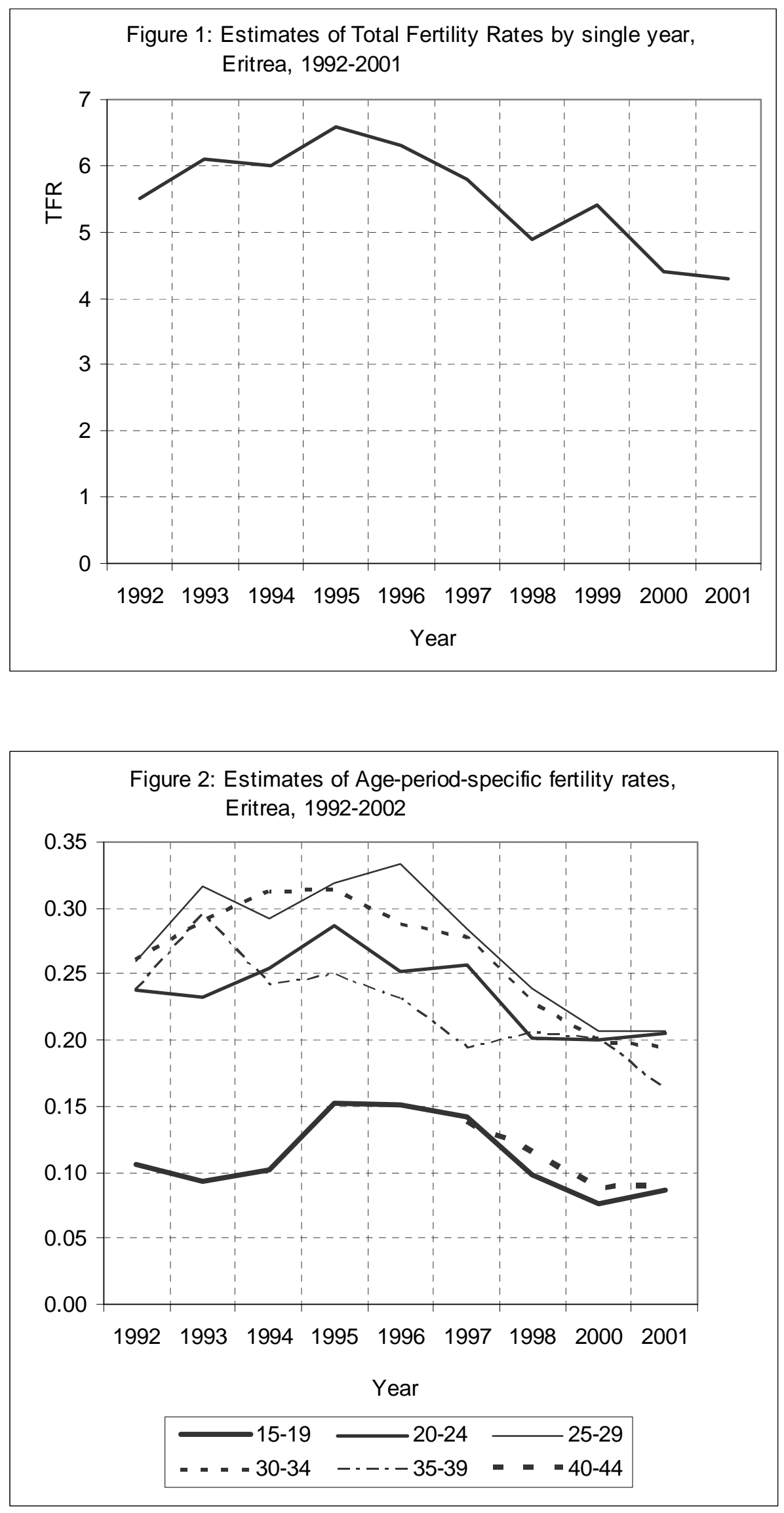
Figure 3: Estimates of Age-period-specific fertility rates,

Rural Eritrea, 1992-2001

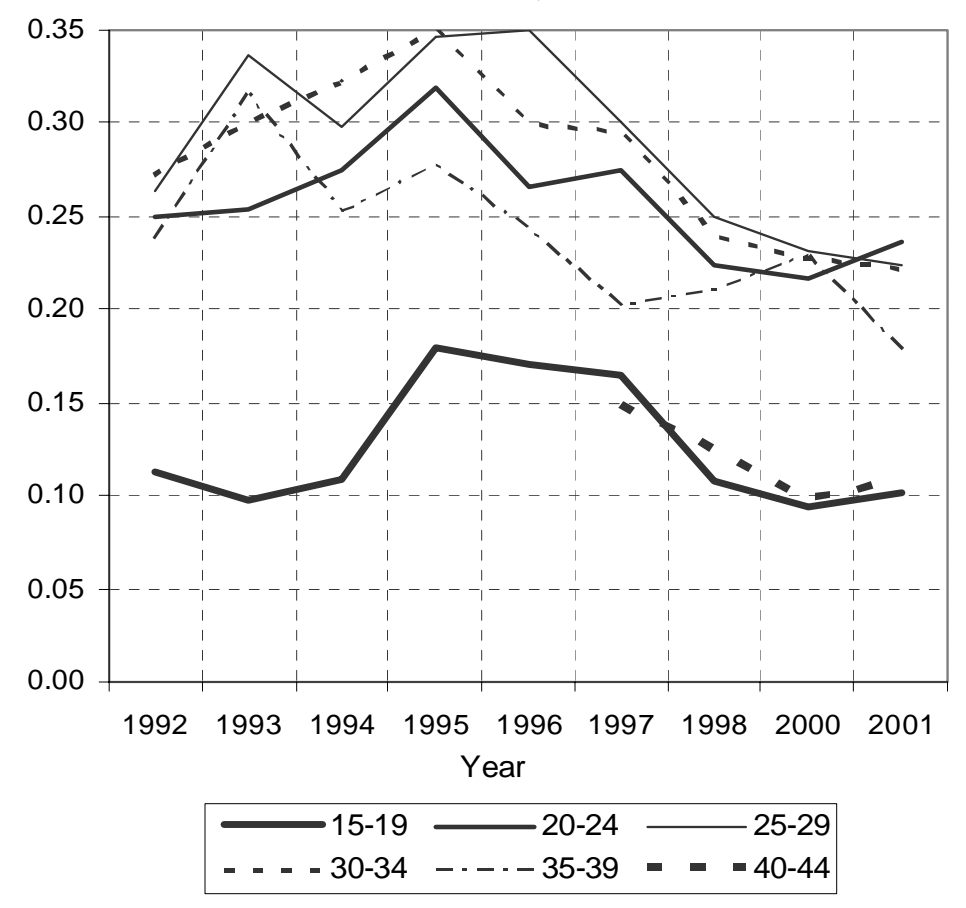

Figure 4: Estimates of Age-period-specific fertility rates, Urban Eritrea, 1995-2001

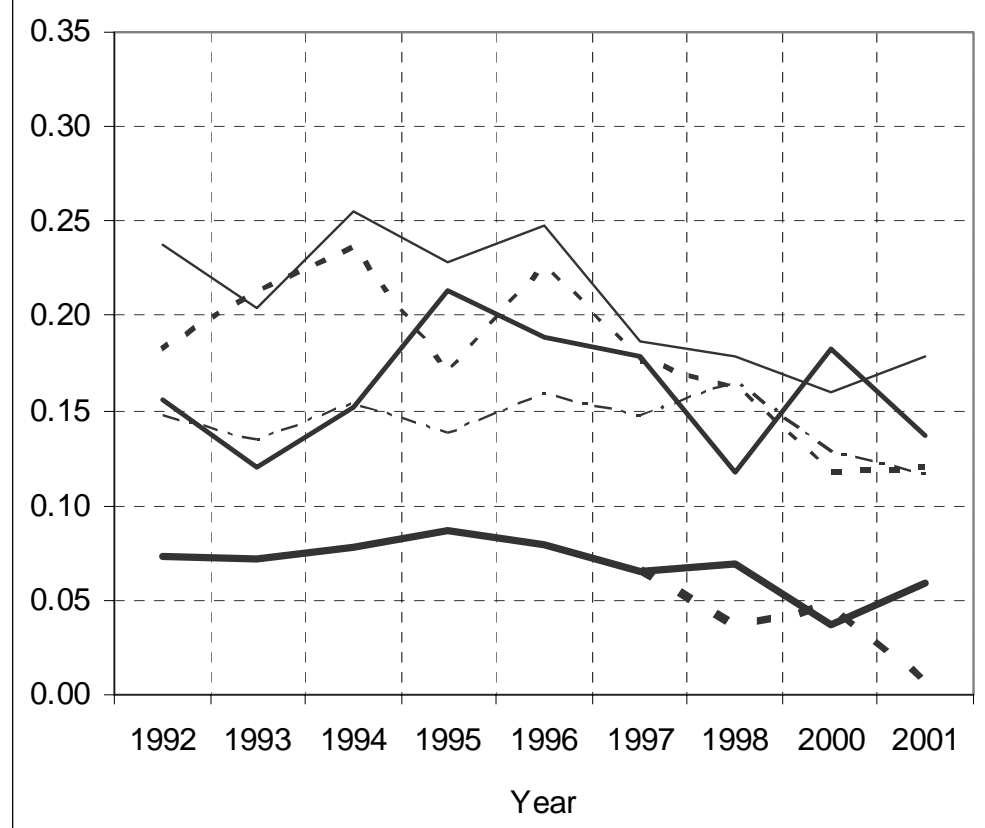

15-19

20-24 - 25-29

- - - - 30-34 - - - - 35-39 = - - 40-44 


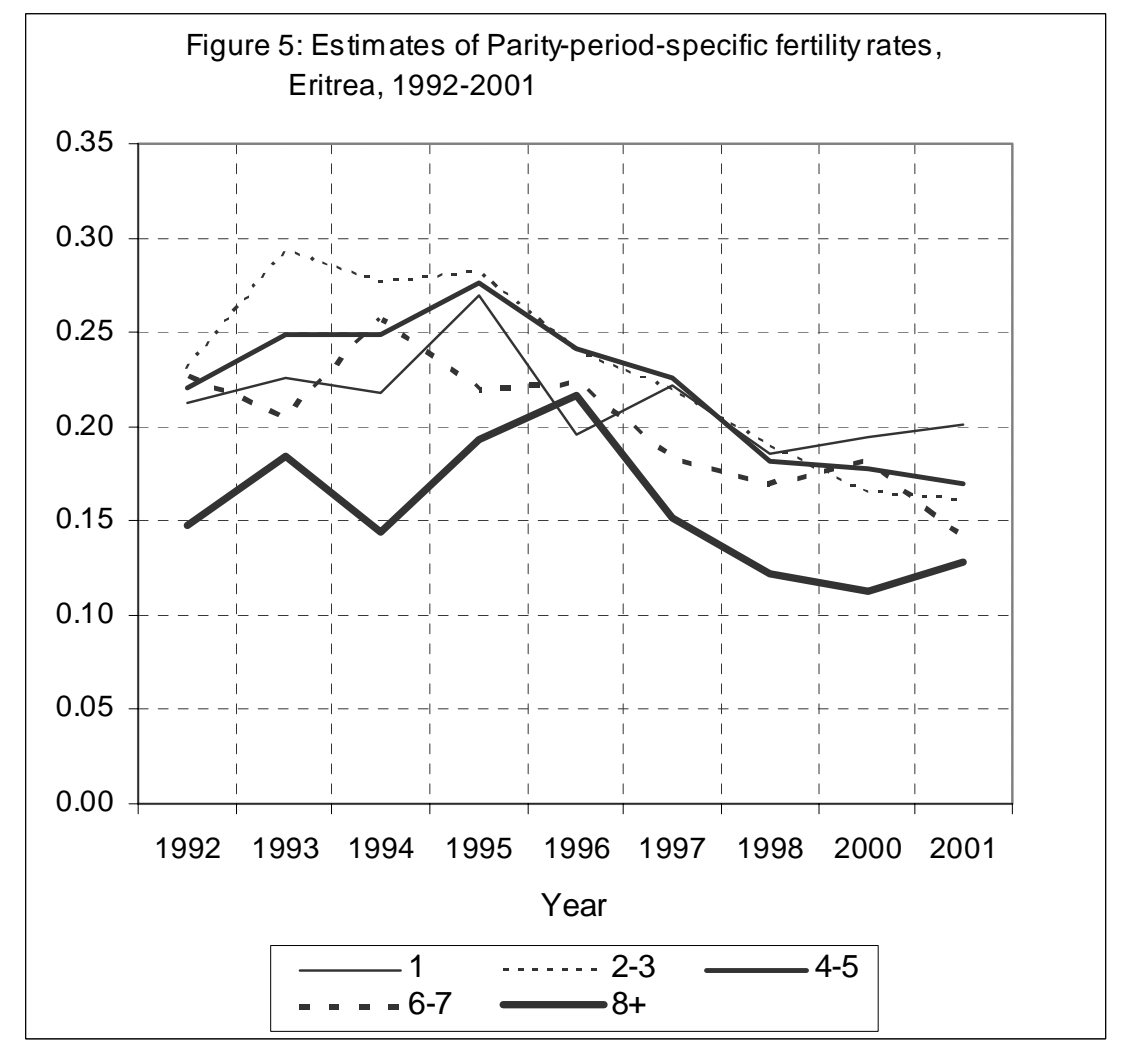

